\title{
Colgajo en isla submental: Experiencia de 2 casos en reconstrucción de base de cráneo lateral
}

\section{Submental island flap: Experience of 2 cases in lateral skull base reconstruction}

\author{
Sebastián Castro M. ${ }^{1}$, Marcela Bugueño V. ${ }^{1}$, José Miguel Contreras R. ${ }^{1,2}$, Felipe Cardemil M.1,3
}

\section{${ }^{1}$ Servicio de Otorrinolaringología, \\ Hospital San Juan de \\ Dios, Departamento de \\ Otorrinolaringología, Facultad de \\ Medicina, Universidad de Chile. \\ Santiago, Chile. \\ ${ }^{2}$ Departamento de \\ Otorrinolaringología, Clínica \\ Alemana. Santiago, Chile. \\ ${ }^{3}$ Departamento de \\ Otorrinolaringología, Clínica Las Condes. Santiago, Chile.}

Los autores declaran no tener conflictos de interés.

Recibido el 25 de julio de 2020. Aceptado el 16 de agosto de 2020.

Correspondencia:

Felipe Cardemil M.

Departamento de

Otorrinolaringología

Departamento de Oncología Básico-

Clínica

Facultad de Medicina, Universidad de Chile.

Santiago, Chile. Email: felipecardemil@med.uchile.cl

\section{Resumen}

La cirugía reconstructiva de cabeza y cuello es una tarea compleja. Existen varias opciones disponibles para lograr buenos resultados, desde colgajos locales hasta colgajos libres microvascularizados. En este reporte presentamos nuestra experiencia utilizando el colgajo en isla submental para la reconstrucción de defectos de tejido blando de base de cráneo lateral posterior a una resección lateral de hueso temporal secundario a diagnósticos oncológicos otológicos. Se presentan datos demográficos, clínicos, quirúrgicos y resultados de dos pacientes intervenidos durante el primer semestre del año 2020, en los cuales se consiguió un adecuado resultado reconstructivo. Este colgajo es una opción confiable y versátil para reconstrucción en cabeza y cuello.

Palabras clave: Colgajo en isla submental, colgajo regional, arteria submental, reconstrucción.

\begin{abstract}
Reconstructive head and neck surgery is a complex task. There are several options available to achieve good results, from local flaps to free microvascular flaps. In this article, we present our experience using the submental island flap for soft tissue defect reconstruction of the lateral skull base after a lateral temporal bone resection secondary to otologic cancer. Demographic, clinical, surgical and outcome data of two patients operated on during the first semester of 2020 are presented, in whom a good reconstructive result was achieved. This flap is a reliable and versatile option for head and neck reconstruction.
\end{abstract}

Keywords: Submental island flap, regional flap, submental artery, reconstruction.

\section{Introducción}

La reconstrucción en cabeza y cuello (CC) es un área esencial en el manejo quirúrgico de cánceres de esta región, donde frecuentemente se tienen que abordar defectos complejos. Colgajos locales, regionales y microvasculares se han desarrollado con el fin de obtener una cobertura confiable, versátil y viable preservando la función ${ }^{1}$.

La reconstrucción de base de cráneo lateral (BCL) supone un desafío quirúrgico, debido a que involucra la cobertura de defectos tanto de tejido blando como óseo, con frecuente exposición de vasos sanguíneos, duramadre, cerebro, pares craneanos (PC). Esta región clásicamente ha sido reconstruida con colgajos regionales pediculados musculocutáneos como de latísimo del dorso o trapecio en isla; o bien, con colgajos libres como anterolateral de muslo o recto abdominal. Sin embargo, en los últimos años, ha ganado popularidad la utilización del colgajo en isla submental (CIS) ${ }^{2}$. La importancia de reconstruir defectos de BCL radica no solamente en dar coberturas a estructuras nobles, sino además, en proveer tejido de soporte para tolerar la eventual necesidad de radioterapia adyuvante. 
A continuación, se presentan 2 casos clínicos donde se utilizó dicho colgajo para la reconstrucción de BCL. Ambos casos clínicos presentan consentimiento informado firmado para la reproducción de historia y fotografías.

\section{Caso Clínico 1}

Paciente de 60 años, sexo femenino, con antecedentes de tabaquismo, índice paquete-año (IPA) 8, consulta por cuadro de 3 meses de evolución caracterizado por otorrea, otalgia derecha persistente y aumento de volumen en meato auditivo externo ipsilateral. Al examen físico destacaba una lesión exofítica, eritematosa, que ocluía completamente conducto auditivo externo (CAE) derecho asociado a compromiso infiltrativo de partes blandas de pabellón auricular, no lográndose visualizar membrana timpánica; sin compromiso de movilidad facial, otros PC, ni compromiso nodal clínico. Se realizó biopsia incisional cuyo resultado informó carcinoma escamoso (CE) moderadamente diferenciado.

Se realizó estudio de etapificación con tomografía computada (TC) de oído, detectando un tumor sólido dependiente de CAE derecho, con un tamaño de 33 × 37 × $20 \mathrm{~mm}$, infiltrando $>0,5 \mathrm{~cm}$ del tercio superior parotídeo; sin compromiso intracraneano, pared medial de oído medio (OM) ni mastoides, contactando articulación temporomandibular
(ATM). Se complementa estudio con resonancia magnética (RM) de oídos y peñasco donde se observó mismo tumor, destruyendo la porción vecina de mastoides, sin diseminación perineural en nervio facial (NF). TC de cuello y tórax no mostraba compromiso nodal ni a distancia.

Este carcinoma fue etapificado, según la clasificación Pittsburgh modificada ${ }^{3}$, como T4N0M0. Se realizó auriculectomía subtotal, resección de hueso temporal lateral (LTBR), conservando pared medial de OM, exponiendo todas las porciones del NF incluidas sus ramas + parotidectomía total con preservación del $\mathrm{NF}+$ disección cervical electiva (niveles IIIII-IV) derecha y reconstrucción con colgajo miocutáneo en isla submental (CMIS). Paciente evolucionó favorablemente, con paresia facial derecha, House-Brackmann (HB) III. En biopsia diferida se confirmó diagnóstico histológico, con compromiso focal periférico de glándula parótida, sin permeación perineural ni vascular; márgenes quirúrgicos libres de neoplasia, el más cercano a $1 \mathrm{~mm}$. Sin metástasis ganglionares en la disección cervical (0/56). Considerando los resultados, se decide proponer tratamiento adyuvante con radioterapia. A seis meses de seguimiento, la paciente presenta colgajo vital, con adecuado volumen respecto al grosor inicial posterior a radioterapia, turgencia normal, sin zonas dehiscentes ni necróticas, con áreas de dermatitis actínica (Figura 1).

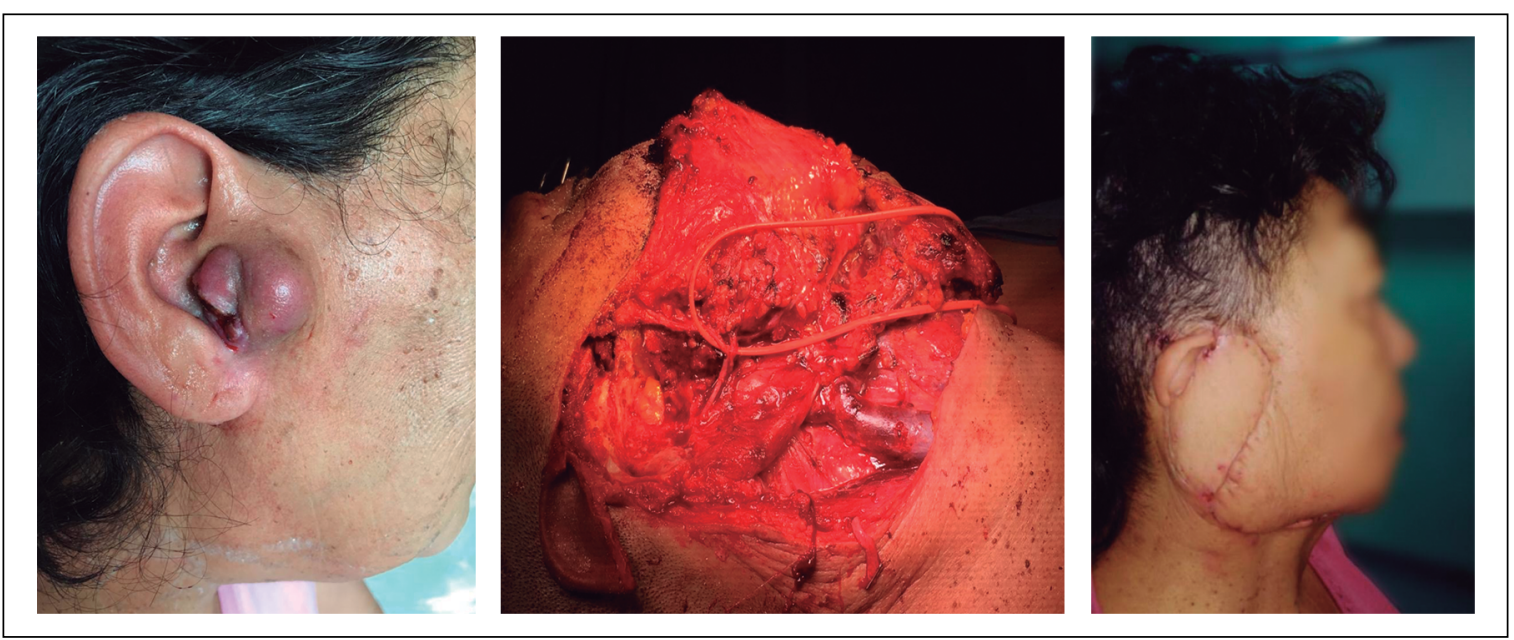

Figura 1. Imagen de paciente con cáncer de conducto auditivo externo derecho preoperatorio, intraoperatorio, y posoperatorio con reconstrucción con colgajo en isla submental derecho. 


\section{Caso Clínico 2}

Paciente de 42 años, sexo femenino, con antecedentes de tabaquismo IPA 24, consulta por cuadro de 18 meses de evolución caracterizado por otalgia derecha progresiva, asociado a prurito intermitente ipsilateral. $\mathrm{Al}$ examen físico se objetivaba una lesión solevantada en región anterosuperior de CAE cartilaginoso derecho de aproximadamente 4 mm de longitud mayor, desde donde se obtiene una biopsia incisional. A la palpación, con induración circunferencial que comprometía pared anterior, inferior y posterosuperior de la mitad externa de CAE; sin compromiso de movilidad facial, ni ATM. La biopsia incisional informó adenocarcinoma bien diferenciado de glándula ceruminosa.

Se realizó etapificación con TC de oídos y cuello objetivando compromiso de CAE cartilaginoso sutil a derecha de tipo circunferencial, con dudosa imagen de erosión mínima de corteza mastoidea; sin otros hallazgos. Se complementó con RM de oídos donde destacaba realce asimétrico en CAE cartilaginoso a derecha de tipo circunferencial, sin compromiso parotídeo, con adenopatía preauricular extraparotídea de $8,9 \times 3,8 \times$ 3,9 $\mathrm{mm}$. TC de tórax, abdomen y pelvis no demostraron lesiones a distancia. Se decidió realizar auriculectomía parcial + LTBR derecho exponiendo todas las porciones del NF incluidas sus ramas + parotidectomía suprafacial + disección cervical terapéutica (niveles Ib a V) derecha y reconstrucción con CMIS en mayo de 2020 (Figura 2).

La paciente evoluciona con paresia facial derecha HB II, con colgajo vital, sin dehiscencia ni isquemia en bordes (Figura 3), con un adecuado aspecto de la cicatriz submental y del contorno facial (Figura 4). El resultado de la biopsia diferida informó carcinoma adenoideo-quístico de tipo cribiforme sólido de 2,2 x 1,6 cm, que comprometía focalmente glándula parótida, con presencia de diseminación perineural; sin invasión vascular, márgenes quirúrgicos negativos y disección cervical sin compromiso tumoral (0/48). Al momento de la redacción de este artículo se encontraba completando radioterapia adyuvante en región temporal para finalizar tratamiento y comenzar seguimiento.
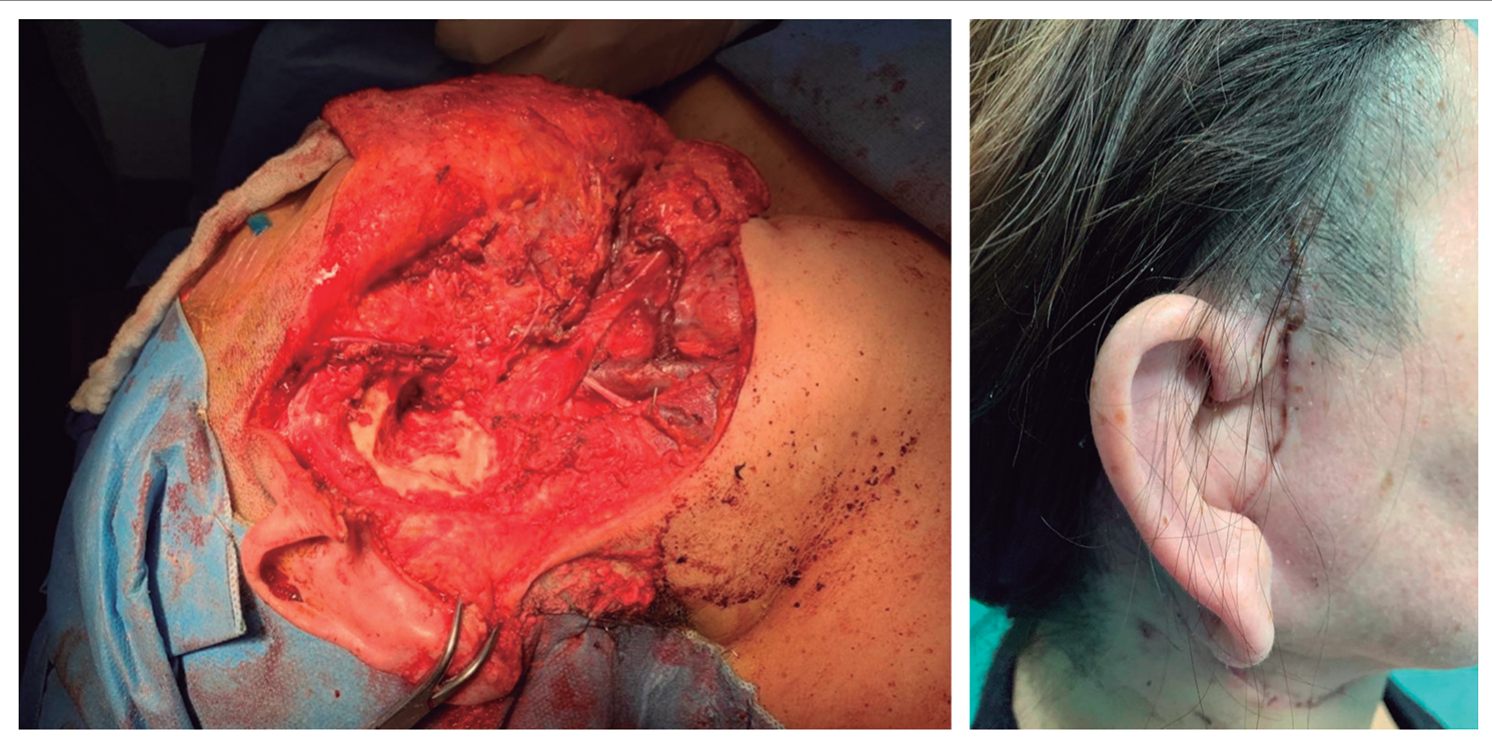

Figura 2. Lecho quirúrgico de resección de hueso temporal lateral (LTBR) derecho con colgajo submental elevado, y aspecto en el posoperatorio precoz. El colgajo se usó de-epitelizado para reconstruir contorno de defecto parotídeo y de defecto de LTBR, y la porción epitelizada se utilizó para reconstruir y obliterar meato y zona preauricular. 

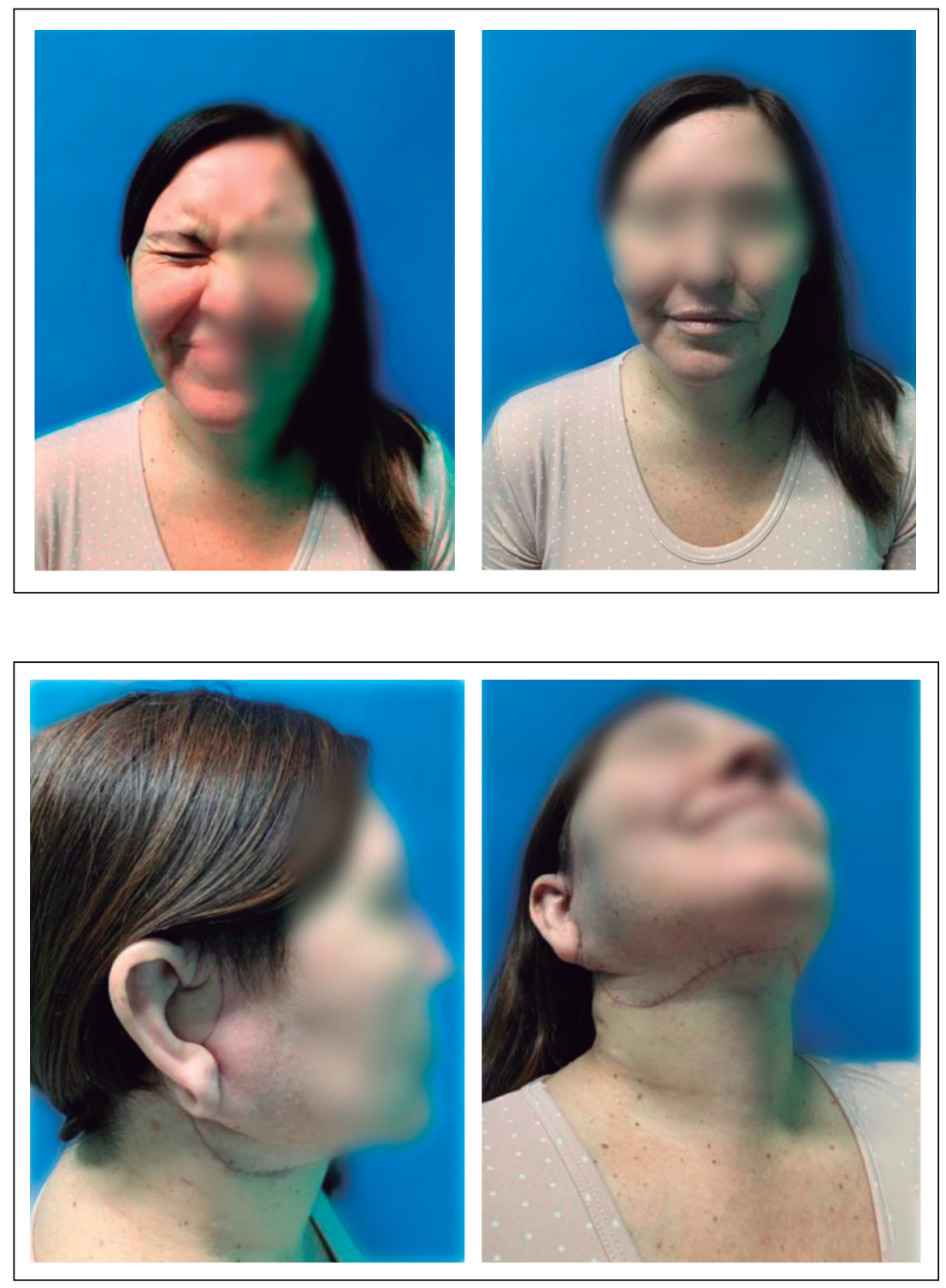

Figura 3. Imágenes a 6 semanas de posoperatorio de resección lateral de hueso temporal derecho con exposición del nervio facial en todo el trayecto intramastoideo y parotidectomía total con preservación de nervio facial y disección cervical derecha, se evidencia paresia facial derecha House-Brackmann II derecha.

Figura 4. Imágenes a las 6 semanas posoperatorias de reconstrucción de contorno facial con colgajo submental en isla y aspecto de cicatriz submental derecha.

\section{Discusión}

El CIS fue descrito por Martin y colaboradores en 1993. Puede ser de tipo pediculado, microvascular libre o híbrido (arteria pediculada y vena con anastomosis microvascular en sitio receptor), con una irrigación de tipo axial dependiente de la arteria submental (AS), rama de la arteria facial (AF) ${ }^{4}$. La AS se ramifica desde la AF 3-15 mm por debajo de la mandíbula, justo arriba de donde la AF emerge por encima de la glándula submandibular ${ }^{5,6}$, infrecuentemente, puede ser rama directa de la arteria carótida externa ${ }^{3}$. Anteriormente, la AS viaja por encima del músculo milohioideo y permanece profunda al vientre anterior del digástrico en el $70 \%$ de los casos y superficial a este en el 30\% restante. La AS suministra ramas al platisma, digástrico, milohioideo, periostio mandibular, perforantes cutáneas (en promedio, 1-2 perforantes) y forma una rica red de anastomosis con la arteria contralateral ${ }^{7}$.

El arco de rotación del colgajo pediculado es amplio, lo que permite la reconstrucción 
de defectos en el tercio medio e inferior facial, incluido BCL, e incluso cuero cabelludo. También se ha descrito su utilización para reconstrucción de defectos en cavidad oral, especialmente lengua, piso de boca y mucosa bucal, sin embargo, nuestro equipo lo utiliza solamente en casos de defectos traumáticos u oncológicos de glándulas salivales con bajo riesgo de metástasis ganglionar, y no en casos de CE mucoso, por el riesgo de transferencia de ganglios con metástasis ocultas. Por su capacidad de ser utilizado como colgajo de tipo libre o híbrido, su versatilidad es aún más amplia ${ }^{4,8,9}$.

La paleta cutánea de este colgajo depende de la piel submental, pudiendo tener un ancho de hasta $7 \mathrm{~cm}$, dependiendo del "test de pinza" preoperatorio, con largo variable, debiendo permitir el cierre primario del sitio donante ${ }^{8}$; por su parecido en color y textura a la piel de la cara, es ideal para reconstrucción de esta región. Además, dado que posee pelo es útil para reconstrucción de áreas como mentón, labio superior, o cuero cabelludo, en pacientes de sexo masculino ${ }^{9,10}$.

El colgajo puede ser fasciocutáneo, pero en el caso de requerir mayor volumen y/o componente óseo, puede ser miocutáneo u osteomiocutáneo, dependiendo si se agrega dentro de la disección músculo milohioideo y/o vientre anterior del músculo digástrico, con o sin una parte marginal de la mandíbula ${ }^{9,10}$. La variante osteomiocutánea es ideal para reconstrucción de defectos de malar o arco subciliar. Este colgajo está contraindicado frente a compromiso nodal clínico-radiológico $(\mathrm{N}+)$ del nivel IA y/o IB ipsilateral al pedículo vascular, por el riesgo de transferir metástasis regionales hacia el sitio receptor. En caso de no tener compromiso nodal clínico-radiológico (N0) y requerir disección cervical profiláctica, como ocurre en pacientes con CE mucosos de cavidad oral, según algunos autores, se podría utilizar para reconstruir esta región ${ }^{9}$. Para esto se debe elevar el colgajo preservando el músculo milohioídeo y disecando completamente el nivel IA, IB y pedículo vascular, lo que podría comprometer la viabilidad del colgajo. Se ha reportado hasta $44 \%$ de recurrencia locorregional con esta técnica: local por la potencial transferencia de ganglios con metástasis oculta al sitio receptor, y regional por potencial falla en disecar todos los linfonodos de los grupos IA y IB del sitio donante ${ }^{11}$. Por este motivo en nuestro abordaje reconstructivo no utilizamos esta alternativa para casos de CE mucoso de cavidad oral. Otra contraindicación corresponde a quemaduras locales, por posible daño endotelial microscópico, que aumentaría el riesgo de falla del colgajo ${ }^{12}$.

Una de las ventajas de este colgajo es su asociación a menores tiempos operatorios, estadía hospitalaria y morbilidad en el sitio donante, en comparación con colgajos libres o regionales, en distintas regiones de CC incluido BCL, haciéndolo una opción atractiva en reconstrucción de $\mathrm{CC}^{1,2}$. Este reporte muestra nuestra experiencia exitosa en cubrir defectos de BCL con CMIS, lo que está replicado en la literatura, mostrando una buena confiabilidad del colgajo, manteniéndose vital hasta en un $100 \%$ de los casos reportados 2 .

\section{Conclusión}

El CIS es una alternativa versátil para la reconstrucción en CC. En BCL es una alternativa importante por los beneficios tanto estéticos como quirúrgicos asociados. Por esto, debiese estar dentro del armamento de todo cirujano de CC.

\section{Bibliografía}

1. Jørgensen MG, Tabatabaeifar S, Toyserkani NM, Sørensen JA. Submental Island Flap versus Free Flap Reconstruction for Complex Head and Neck Defects. Otolaryngol Head Neck Surg. 2019;161(6):946-953. doi: 10.1177/0194599819875416.

2. Howard BE, Nagel TH, Barrs DM, Donald CB, Hayden RE. Reconstruction of Lateral Skull Base Defects: A Comparison of the Submental Flap to Free and Regional Flaps. Otolaryngol Head Neck Surg. 2016;154(6):1014-1018. doi: 10.1177/0194599816634296.

3. Moody SA, Hirsch BE, Myers EN. Squamous cell carcinoma of the external auditory canal: an evaluation of a staging system. Am J Otol. 2000;21(4):582-588.

4. Martin D, Pascal JF, Baudet J, et al. The submental island flap: a new donor site. Anatomy and clinical applications as a free or pedicled flap. Plast Reconstr Surg. 1993;92(5):867-873.

5. Faltaous AA, Yetman RJ. The submental artery flap: 
an anatomic study. Plast Reconstr Surg. 1996;97(1):5662. doi: 10.1097/00006534-199601000-00008.

6. Magden O, Edizer M, Tayfur V, Atabey A. Anatomic study of the vasculature of the submental artery flap. Plast Reconstr Surg. 2004;114(7):1719-1723. doi: 10.1097/01.prs.0000142479.52061.7d.

7. Nguyen K, Gilde J, Inman J. Submental island flap and bone variation. Operative Techniques in Otolaryngology. 2019; 30 (2): 101-105. doi: 10.1016/j. otot.2019.04.003.

8. Parmar PS, Goldstein DP. The submental island flap in head and neck reconstruction. Curr Opin Otolaryngol Head Neck Surg. 2009;17(4):263-266. doi: 10.1097/MOO.0b013e32832cee83.

9. Howard BE, Nagel TH, Donald CB, Hinni ML, Hayden RE. Oncologic safety of the submental flap for reconstruction in oral cavity malignancies. Otolaryngol Head Neck Surg. 2014;150(4):558-562. doi: 10.1177/0194599814520687.

10. Bayon R, Davis A. Submental Flap for Soft Tissue Reconstruction following Radical Parotidectomy. Otolaryngology Head and Neck Surg. 2019; 160(6): 1130-1132. doi: 10.1177/0194599819827822.

11. Cariati $P$, Cabello Serrano A, Marín Fernández AB, Pérez de Perceval Tara M, Juliá MA, Ildefonso Martínez Lara M. Is submental flap safe for the oncological reconstruction of the oral cavity?. J Stomatol Oral Maxillofac Surg. 2018;119(4):284-287. doi: 10.1016/j.jormas.2018.06.006.

12. Cheng A, Bui T. Submental island flap. Oral Maxillofac Surg Clin North Am. 2014;26(3):371-379. doi: 10.1016/j.coms.2014.05.005. 